\title{
Audiovisual Resources in Formal and Informal Learning: Spanish and Mexican Students' Attitudes
}

\author{
Javier Fombona $^{1} \&$ Maria Angeles Pascual ${ }^{1}$ \\ ${ }^{1}$ Faculty of Teacher Training and Education, University of Oviedo, Spain \\ Correspondence: Javier Fombona, Faculty of Teacher Training and Education, University of Oviedo, Spain. Tel: \\ 34-985-109-553. E-mail: fombona@uniovi.es
}

Received: November 18, 2012 Accepted: December 3, 2012 Online Published: December 12, 2012

doi:10.5539/ies.v6n2p1 URL: http://dx.doi.org/10.5539/ies.v6n2p1

\begin{abstract}
This research analyses the evolution in the effectiveness of media messages and aims to optimize the use of ICTs in educational settings. The cultural impact of television and multimedia resources is increasing as they move to the Internet with ever greater quality. The integration of visual narrative techniques with multimedia playback capabilities of the Internet is creating an innovative model of knowledge transfer that contrasts with some traditional school approaches. So, the introduction of audiovisual elements and multimedia resources in the classroom seems to be more effective than other "traditional" methodologies. In order to assess and test this initial hypothesis, this research relies on empirical data from a survey conducted among more than 400 students from Spanish and Mexican schools. Besides considering the relation between the time spent watching multimedia resources and students' academic performance, this paper analyses the possible benefits of learning strategies that include multimedia and audiovisual elements. Above all, we suggest that teachers should use educative methodologies that trigger emotional responses, in the same way as entertainment and multimedia resources do.
\end{abstract}

Keywords: media, audiovisual resources, informal learning, multimedia literacy, ICTs, teaching/learning strategies

\section{Introduction}

\subsection{Importance of Audiovisual Materials}

In the context of the global era and the knowledge society, new technologies have had an extraordinary impact in the way people access information on a daily basis. The effects of globalization, together with the immediacy brought about by the Internet, have completely changed the way people communicate in the 21 st century: the development of the Web 2.0 promoted the interaction among users and allowed for a shift in the role of consumers into prosumers, with users undertaking a more active role in the creation, edition and distribution of multimedia and audiovisual contents. Furthermore, with the Web 4.0, the Internet has become ubiquitous and today we can access online contents not only from a desktop or a laptop but also using all kinds of handheld and mobile devices. Arguably, the media have become a powerful and influential tool as long as communication and information are concerned, in this sense, the development of audiovisual narrative and the power of visual images and messages have largely contributed to consolidate and reinforce the influence media have in our society.

In the last decades, 1980 to 2012, we have witnessed the rising of "digital natives" who are able to command new technologies from very early stages. In this framework, the application of cutting-edge multimedia and audiovisual resources in the educational setting can report interesting results from the point of view of research and also in order to improve and optimize the learning process. Since we live in a technology-driven society, the introduction of new methodologies and approaches has to be listed in the agenda of educational institutions. The use of media in the classroom is a thrilling research line that has to be further explored and studied, in particular, the introduction of audiovisual resources in education can render positive results in order to optimize the learning process and prevent academic failure and early school leaving.

Ibero-American countries have been tackling the inclusion of new technologies in education for some time now, investing in tools that are not always supported by an effort to understand new audiovisual contents. Most 
educational policies focus on the integration of information technologies inside the classroom, paying less attention to specific audiovisual actions. On the other hand, recently the number of $\mathrm{PhD}$ dissertations on audiovisual media has increased while there is a downwards tendency in the field of IT (Tab. 1).

Table 1. PhD dissertations on IT and multimedia (Spain). Source: Teseo Spain

\begin{tabular}{lllllll}
\hline PhD dissertations & \multicolumn{2}{l}{ Since 1976 to 2011 } & \multicolumn{2}{l}{ Since 2006 to 2008 } & \multicolumn{2}{l}{ Since 2008 to 2011 } \\
\hline Informatics & $137(20.0 \%)$ & $49.9 \%$ & $19(20.7 \%)$ & $33.7 \%$ & $25(17.9 \%)$ & $27.1 \%$ \\
Computer & $205(29.9 \%)$ & & $12(13.0 \%)$ & & $13(9.2 \%)$ & \\
Multimedia & $163(23.8 \%)$ & $50.1 \%$ & $23(25.0 \%)$ & $66.3 \%$ & $47(33.6 \%)$ & $72.9 \%$ \\
Video & $181(26.3 \%)$ & & $38(41.3 \%)$ & & $55(39.3 \%)$ & \\
Total & $686(100.0 \%)$ & $100.0 \%$ & $92(100 \%)$ & $100.0 \%$ & $140(100.0 \%)$ & $100.0 \%$ \\
\hline
\end{tabular}

Multimedia contents are transmitted through information technologies and have become on their own a special kind of narration. Rapid development integrating visual communication features of information and communication technologies (ICT) with technological forces has converged in multimedia (Okamoto, Cristea \& Kayama, 2001). It reorganizes basic knowledge construction, the way in which concepts and language are presented, while it centers contents and forms of transmission on the individual (Coulangeon, 2009).

Multimedia integration of audiovisual and informatics should lead to an important transformation of both teaching and learning paradigms (Prensky, 2008). This trend is supported by technological advances, increase of Internet bandwidth, and integration of multiple resources in order to improve the learning process, tailored teaching strategies and the study process through the interactive web. All of them give origin to new models that are not free of danger. Educational projects nowadays require different educational strategies, singularly and specifically attuned to the dynamics that allow for the success of the media. Social evolution requires an ongoing renewal of educational forms and content, and also the review of all options in technological terms (Pelgrum \& Voogt, 2000; Pelgrum, 2001; Rockwell \& Singleton, 2007; Jones, Dean \& Hui-Chan, 2010; Hwang, Kuo, Yin \& Chuang, 2010).

Formal strategies of transmission have become by themselves part of the subject matter transmitted, forming one unique coherent message, reinforcing the idea of media becoming the message, and opening the possibility of other innovative implementations (Trachtman, 2008). So, we understand that there is no longer a clear line between content and the medium it carries, and now, it is difficult to differentiate computer education, Internet, multimedia, video, virtual worlds, etc. (Hassett, 2007; Liu, Wang \& Liu, 2009).

\subsection{Improving the Effectiveness of Media Messages}

Which contents, media and narrative strategies better affect our culture? We can see that Internet and multimedia are effective in transmitting their messages: they have become pseudo educators, developing an educational process through a world of attractive images that usually respond to the interests of those who control mass media (Chan et al., 2006; Fombona, 2008). Narrative multimedia techniques and their strategies have become not only a parallel school, but also a reference model that seems to impose itself on the traditional educational model (Gernard \& Klinger, 2007; Miglino \& Walker, 2010).

The effectiveness of these strategies can be commonly perceived in everyday dialogues, where they create a specific network of personal values $(\mathrm{Fu}, 2006)$. Knowledge takes on new forms, as media and platforms are connected to each other, this leads to new working and learning methodologies (Upadhyay, 2006; Proserpio \& Viola, 2007). The new channels determine ways to organize content, as it is reflected by the similarity between most messages from the media that build specific schools of thought. How can the teacher work in this context?

Multimedia messages continue to dominate communicative environments, more than 254 minutes per individual/day of television is an average that seems to increase during crisis periods (Kantar, 2011). The amount of time spent in front of the TV screen is moving from traditional television devices towards audiovisual formulas designed for specific target groups, as YouTube or Facebook, where messages respond to the concerns of the issuer and user. Today's consumers -especially young people- tend to watch fewer TV shows and, instead, prefer to watch small fragments of text, video, audio or images from the Internet in mobile devices. This is a relevant development since Web 2.0 not only allows for passive viewing, but also makes it possible to create, upload and distribute our own tokens (Liaw, Hatala \& Huang, 2010). Virtual words are, above all, information 
systems predicated on the visual icon. Generally, the user doesn't need to leave home -just needs to be near his laptop or on his cell phone- to partake of the experience. The development of mobile technology has contributed to this (Shahid \& Tang, 2007; Meawad \& Stubbs, 2008; Marin \& Mohan, 2009; Jones \& Healing, 2010).

Traditional audiovisual experiences (watching a movie's projection, television, and so on) seem to have reached a turning point, and now, once the problem of transmission has been solved, the audiovisual should be studied within the realm of telematics or ICT's -networks, Internet, and mobile devices-. Also, methods for data compression and new digital formats increase ease of the individual distribution of all kind of videos and sounds (Waard et al. 2007; Mann, Wong \& Park, 2009).

The activity of our students in the new virtual spaces has increased (Orland, 2006; Briggs, 2007). Nowadays, the interchange of data, information and knowledge, within an audiovisual paradigm is frequent, as it is the case in chat rooms, Facebook, Twitter or Second Life (Ward, 2008; Andrejevic, 2009; Eren et al. 2010; Everhart, 2010; Marsh, Mitchell \& Adamczyk, 2010; Chenail, 2011). We can observe the supremacy of audiovisual material in YouTube's statistics. For instance, Justin Bieger's video, "Baby ft. Ludacris", has been watched more than 800 million times.

The efficiency of this new way of writing with ICT's has been potentiated by the inclusion of commercial interests of companies that manage or distribute the messages. Generally speaking, contents tend to be concrete and follow marketing rules in order to be successful (Ferrell \& Hartling, 2006; Yen, 2008). A reason behind this situation is profitability: the market model of television is based on ads, commercial products of music records, movies, video games, cosmetics, liquors, etc. Similarly, there are ads in "free email" and social network services like Facebook, Twitter, and YouTube. Marketing aims to creating loyalty. Quality management and customer oriented models try to attract people to buy their messages (Murgatroyd \& Colin, 2002).

Sevillano-Garcia (2008) indicates that the new educational models must review their implementation, focusing on strategies that empower the effectiveness of educational actions. Accordingly, we want to use in education some of the effective media strategies. We have established as our primary goal the analysis of variables related to the perceived effectiveness of school messages in contrast to those of multimedia. Our aim is to make educational messages more effective.

\section{Method}

\subsection{Goals and Methodolgy}

This research is intended to find effective strategies that media can afford in order to improve the use of ICTs in schools both in content and delivery. To reach this goal, and relying on a solid theoretical framework, we have built a questionnaire with propositions related to the perceived effectiveness of message transmission, for both multimedia resources and schools. They were organized in 7 propositions, each one evaluated for multimedia and schools over a Likert's scale with four possible answers: $0=$ Never; $1=$ Almost Never; $2=$ Sometimes; $3=$ Almost Always; $4=$ Always. They are briefly described in the following paragraphs.

Our research brings together the main strategies that are found in media, and suggests ways to use some of these strategies in the school context. The strategies focus on efficiency.

About how media present their messages:

Multimedia content usually addresses entertainment. From this premise we posed three propositions about the Topic 1 They offer a great amount of entertainment.

- Media overdramatize its contents. In this sense, audiovisual media focus on the sphere of feelings, fascination and fantasy. From this point of view, we propose the following Topic 2: Contents can elicit emotions.

- Multimedia resources provide data from the ubiquity with random, diffuse presentation. According to this, the following proposition was made, Topic 3: Contents are not organized.

- Goals for media are economic and materialistic in the short term, together with immediate solutions. Immediate answers to vital questions: problems and their easy answers, happiness is promised by social media through products found in the supermarket. Ephemeral, easy descriptions are provided creating a superficial, mosaic knowledge. They quickly re-organize the reality into good or bad elements. Two propositions are submitted in our questionnaire about this Topic 4: Contents are dense and deep; Contents make me think.

Particularly, audiovisual media do not require a response from their audience -which receives messages in a passive way-. It is unnecessary to think over easy and already assimilated messages (Topic 5). Accordingly, the following propositions were stated: Contents are easy to understand; Contents demand efforts on my part and make me do things. 
- The technological discourse is based on iconic forms and limits reading to complementary forms of expression. The audiovisual model solves questions through images efficiently, it is a self-explanatory specification -elements will be integrated into the images themselves to explain contents- (Topic 6). Accordingly, we created the propositions: Contents are focused on texts; Contents are focused on images.

- The message is surrounded by a recreational and dynamic sphere. Its procedures are very dynamic and aggressive. It is performance and exaggeration that counts (Topic 7). Accordingly, the following proposition was stated: Contents are presented in a fast way.

\subsection{Participant (Subject) Characteristics}

Also, the following social-demographic questions were included: Age: Number in years; Gender: Male or female; Country: Spain or Mexico. Average daily time spent viewing television or as user of other multimedia: Number in minutes.

To verify the content validity of the questionnaire we used a theoretical foundation improved through repeated use and empirical evidence. A Cronbach Alpha greater than 0.8 was obtained in all the cases, indicating acceptable internal consistency. The Pearson correlation coefficient resulted in values close to 1, suggesting a strong positive linear correlation between variables.

The survey was conducted online and it was answered by 442 volunteers working in higher education institutions from Spain (Universidad de Oviedo) and Mexico (Universidad Nacional Autonoma de Mexico). Twelve of them were considered invalid since there was a significant difference between the repeated questions used for control. Resulting data were codified through Microsoft Excel and processed with the statistics program Statgraphics Centurion.

The election of Mexico and Spain's samples was made on cultural affinity, Latin references, existing a mutual acknowledgement in the educational institutions and in both contexts the secondary education is considered mandatory on the most base levels.

\section{Results}

\subsection{Findings: Typology of the Analyzed Sample}

The instrument was answered mostly by university students aged 18 to 25 , as shown in Figure 1 .

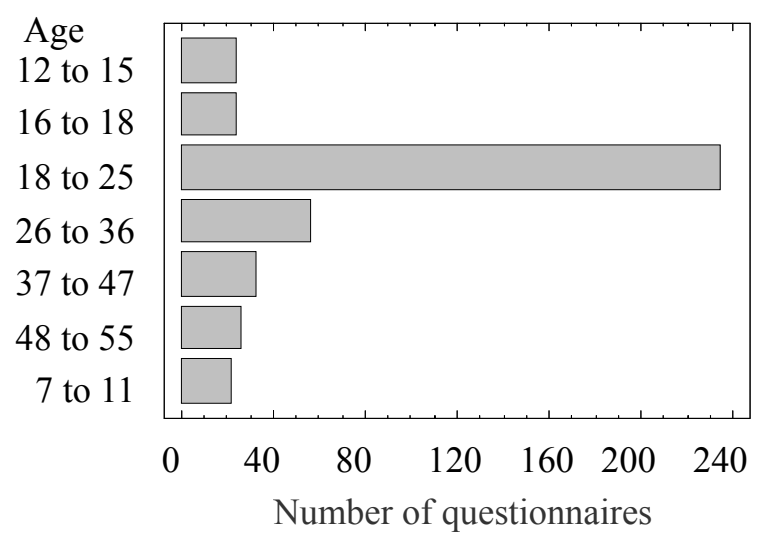

Figure 1. Age of respondents

By nationality, 260 students were Spanish and only 182 were from Mexico. Spanish students were distributed in 194 men and 248 women. The average time spent watching multimedia tends to be higher in Spain than in Mexico (Fig. 2). $79 \%$ of Spanish respondents watch audiovisuals for more than an hour a day, while in Mexico only $56 \%$ did so. 


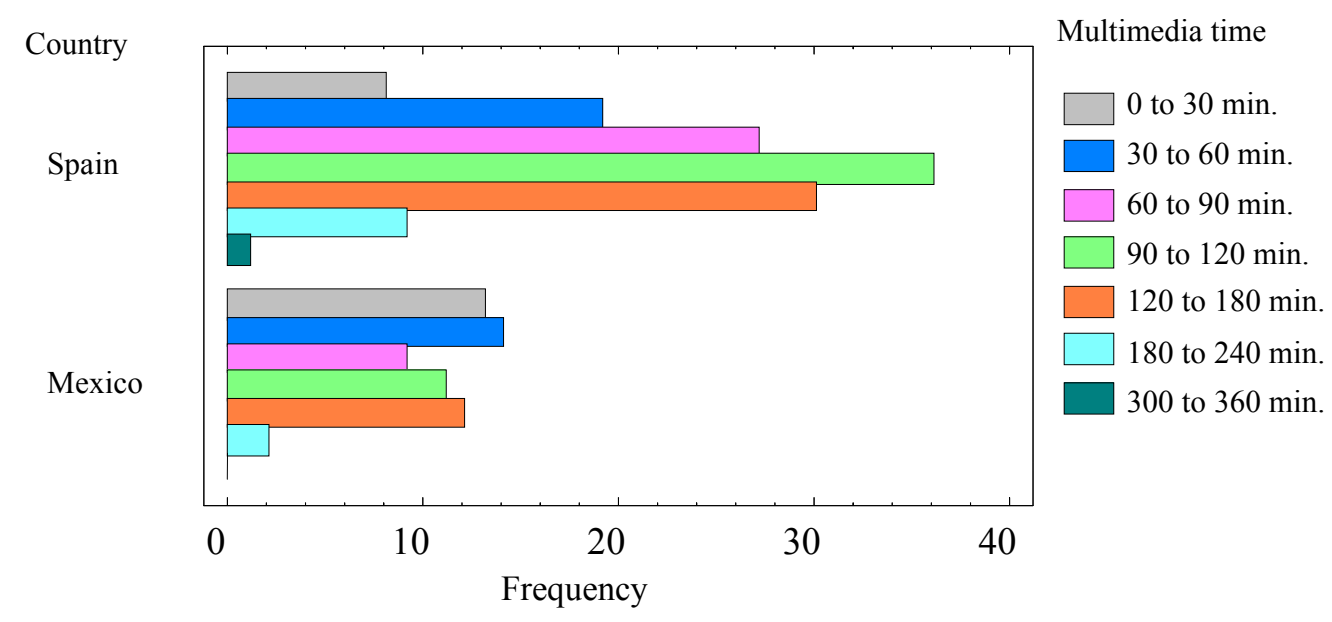

Figure 2. Average time viewing multimedia by country

Average time spent watching multimedia is similar for men and women (Fig. 3): $68 \%$ of men and $72 \%$ of women watch multimedia for more than an hour a day.

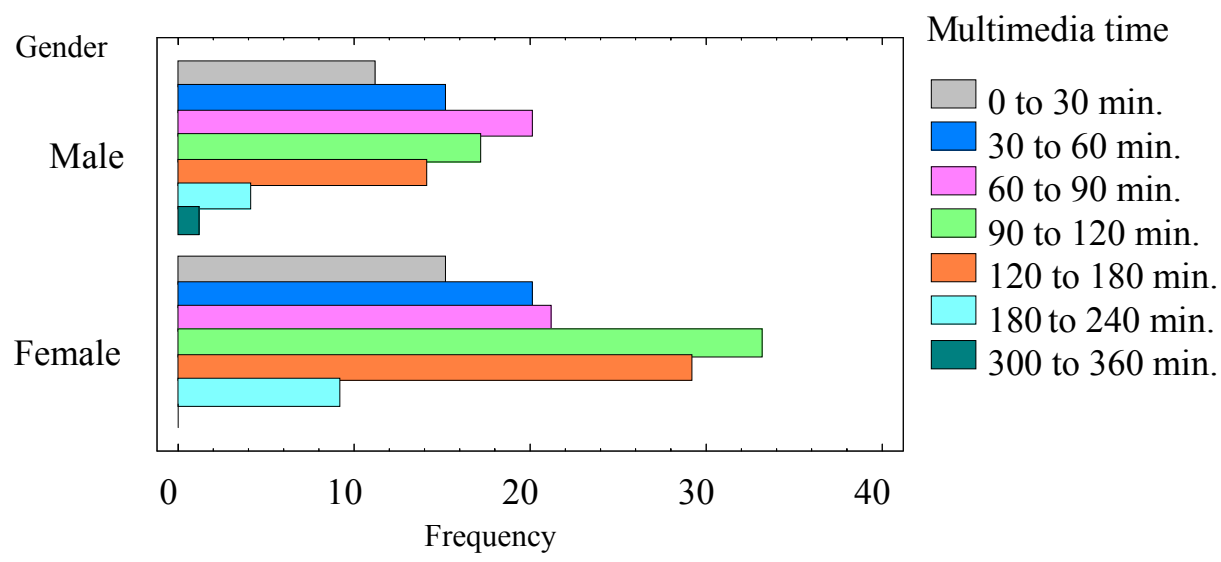

Figure 3. Average time watching multimedia and gender

\subsection{Time Watching Multimedia Resources and Academic Performance}

Academic performance: Selection of one of these options, numbered in ascending order: 1) Most of the time I have troubles understanding the lessons; 2) Sometimes I have troubles understanding the lessons; 3) I have no problem understanding the lessons; 4) I always achieve good or excellent results.

Students who spend less time watching TV or using audiovisual technologies are those who succeed in more disciplines obtaining better grades (Fig. 4); $40.4 \%$ of the students who spend less than an hour a day usually get good or excellent grades. This percentage only accounts for $12.5 \%$ for those students who spend more than 2 hours per day using audiovisual technologies or TV. Thus, $63.41 \%$ of respondents who watch more than 60 minutes of audiovisual material per day perceive themselves as having a problem to succeed in some academic subjects, confirming the inverse relationship between the watching time and the perceived academic performance (Huston, 1999). 


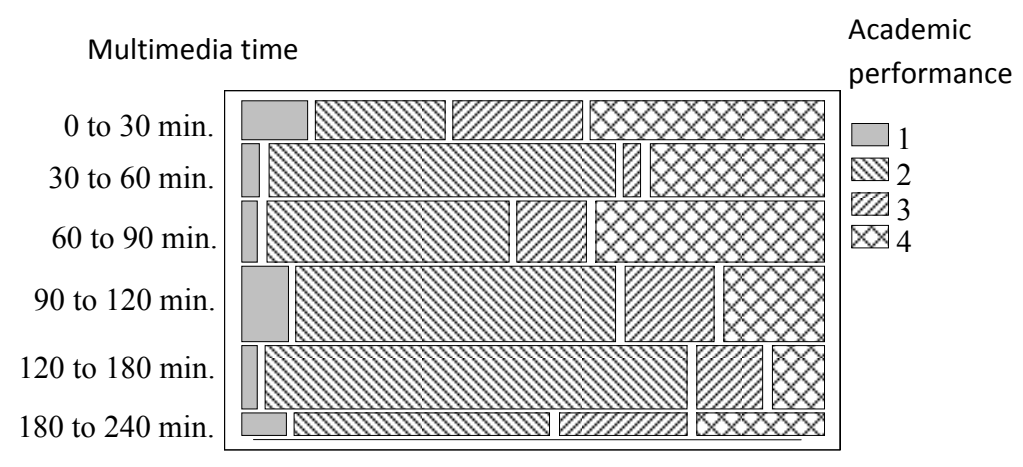

Figure 4. Time spent on multimedia vs. academic performance

\subsection{Results of the Topics}

\subsubsection{Proposition}

\section{1) Source of Entertainment}

Multimedia activities are seen "always" or "almost always" as a source of entertainment by $66 \%$ of students on the survey, and only $44 \%$ think educational centers are sources of amusement. Those who say they are "never" or "almost never" distracted by multimedia also say that the educational center is an entertainment source in $87 \%$ of cases.

For students who are watching audiovisual material more than 90 minutes per day, media are seen as entertaining "always" or "almost always" (85\%), whereas the school is perceived as funny only in $37.3 \%$ of the cases. As for students who use audiovisual materials less than 90 minutes per day, this seems "always" or "almost always" entertaining (44\%), while school seems to be amusing in $56 \%$ of cases. For students who "never" or "almost never" found school entertaining, then only $22 \%$ had good grades, and $66 \%$ usually failed some subjects. Among the students who had some problems with their grades, $60.8 \%$ see more than 90 minutes audiovisual material per day, and they find school entertaining only $39.1 \%$ of the time.

\subsubsection{Proposition}

\section{2) Contents elicit emotions}

Multimedia contents elicit emotions "sometimes", "always" or "almost always" in 90\% of the cases surveyed, and content in schools elicit emotions in $72 \%$ of cases. These figures suggest that educational centers are less likely to be associated with emotions, and this emotional dimension can be used to produce effective messages. Media overdramatize its contents; in this sense, audiovisual media focus on the sphere of feelings through fascination and fantasy.

Students who watch audiovisual material more than 90 minutes per day feel emotions "always" or "almost always" in $53.3 \%$ of cases, whereas in schools this is only $15 \%$. Among the students who watch less than 90 minutes per day, the emotional response difference between school and audiovisual material decreases, rating them at $30 \%$ and $25 \%$ respectively (eliciting emotions "always" or "almost always").

\subsubsection{Proposition}

\section{3) Organization of content}

Contents taught in schools are perceived as organized in most cases (60\%), while this figure decreases to $37 \%$ for contents delivered through audiovisual technologies. This result seems to be consistent with the view that educational centers follow a systematic, structural, linear planning (established by a series of policy documents, programs, etc.). Multimedia provides data from the ubiquity of modern-day information, often presented randomly and in a diffuse way. 


\subsubsection{Proposition}

4) Density and complexity of contents

Contents at educational centers are perceived as complex and deep "always" or "almost always" $59.8 \%$ of the times, while for multimedia, the percentage drops to $14 \%$. In educational centers, contents make students think frequently ("always" or "almost always") for $67 \%$ of respondents ( $79 \%$ in the students with subjects deferred), while audiovisuals promote thinking just in $17.5 \%$ of them. These percentages support the results of Proposition 1 where students perceived contents delivered in educational centers as "dense and deep".

\subsubsection{Proposition}

5) Easiness of comprehension and degree of effort required

Multimedia contents are "always" or "almost always" easy to understand for $76 \%$ of the students covered by the survey; as for school contents, this perception was reduced to $41 \%$. This result could be related to the perceived superficiality of audiovisual content, as well as traditional teaching problems in educational centers. In the case of multimedia contents, effort is required "always" or "almost always" in 5\% of the respondents, while this percentage increases to $78 \%$ for contents taught in educational centers.

\subsubsection{Proposition}

\section{6) Expressive force of images}

In educational centers, contents are focused on the text "always" or "almost always" in $83 \%$ of cases, while in multimedia content this is the case for only $5 \%$ of respondents. This may be explained by the Spanish and Mexican schools overuse of textbook-based contents that shuns additional images. Unlike the previous item, multimedia content is perceived as focused on images "always" or "almost always" in $89 \%$ of the times; while for educational centers this figure is only $10 \%$. These values are consistent, but highlight the need of incorporating images in educational narrative as an additional resource.

\subsubsection{Proposition}

7) Speed of content presentation

As far as the content of multimedia is concerned, this is seen as being presented "always" or "almost always" quickly for $67 \%$ of respondents, while in educational centers this is the case for only $28.8 \%$ of respondents.

\section{Discussion}

Topic 1. We agree with Kenwat and Bullen (2001) and Samaniego (2008) on the need to bring entertainment into learning strategies. Multimedia strategies are oriented toward the effectiveness of entertainment, while the traditional formative model concentrates its goals on building knowledge. Broadly speaking, audiovisual resources contribute to create appealing and amusing messages that are welcome by students; whereas schools are sometimes perceived as boring by students, the use of media can effectively improve the context of the learning process and contribute to fight academic failure. However, combining the effort required to assimilate and develop knowledge with the entertainment strategies offered by the media is not a straightforward task (Renes, Mussaers \& Woerkum, 2011).

Topic 2. Teachers should not forget the emotional aspect. We must also respond to the immediate interest of students. Media offer us instantaneous solutions to vital questions: some problems and their solutions repeat themselves in similar schemes of values and ways of living (Spring, 2008). Media's goals are economic and material, short-termed, with immediate solutions. It seems that happiness could be reached through products easily found at the supermarket (Robinson \& Martin, 2008). On the other side, solutions proposed by the teacher create a medium- and long-term vision of students' lives. Teachers look for long-term goals: the formation and development of the individual, and in all cases, try to seek solutions to personal problems through methodological approaches.

Topic 3. The confluence of media, often called multimedia, seems to have the knack for ubiquity of data. Data presentation is random, and diffuse: we may see at first an earthquake, followed by a sports game and then a reality show. Instead, classroom experiences seek to follow a structured, linear and systematic plan, ruled by a strict system of documentation and programming (Richardson, 2006). We think we should leave room for surprise and the unexpected.

Topic 4. Multimedia resources frequently offer simple and ephemeral descriptions, which create superficial knowledge and quickly reorganize reality into good or bad elements. Its shapes are dynamic, aggressive, and full of fun and exaggeration. Contrary to this, the classroom is a framework for coordinated and deep knowledge 
(Winn, 2002), rigorous studies that require long descriptions and complex ideas to understand multiple dimensions of problems. Reflexive abstraction requires a deep rational thought. Interest is centered in reality, the scientific dimension of the problems, the context and depth of phenomena (MacDonald, 2006). To avoid the potential fatigue of hearing and understanding audiovisual descriptions, these tend to be simple and brief, creating a "mosaic" or a superficial coat of knowledge.

In this sense, the works by Caspi, Gorsky and Privman (2005) are a relevant source to be considered here. It was found that reading comprehension strategies are inappropriate for viewing comprehension; presumed theoretical advantages associated with instructional video may in fact turn to be disadvantages, as the medium does indeed influence the message (mismatching medium and message may have deleterious results on students' cognitive and affective outcomes and surface-level orientations to study may be hindered by video resources).

Topic 5. Multimedia does not require any activity from the user, who receives the messages in a passive way. This passivity effect generated by the media is more noticeable in young audiences (Hill, 2011), although additional causes may be found in order to explain this sedentary tendency. It becomes unnecessary to reflect on messages that can be easily "digested" (Hall, 1981). The teacher, on the other hand, requires students to react actively: the effort and profound reflection in the classroom require a greater amount of concentration.

Topic 6. There is a clash between the realistic presence of iconic elements and deep rational thinking. Technological speech focuses on merely iconic shapes and reduces reading to complementary expressions (Gamboa \& Reina, 2006), while the traditional didactic process focuses on reading written documents. The audiovisual model is effective when it solves questions through images; it is a self-explanatory method. The images must contain in themselves all the elements that narrate the entirety of their contents (Castillo, 2004).

Topic 7. The discrepancy between these two percentages may be explained by the fact that educative centers present structured information, which come by much slower than that obtained through Google searches or the fast and steady stream of television images for instance. Students are used to receiving a constant and intense flow of information sources coming from social communication media and the multiple options provided by the Internet. We agree with Prensky (2008) and Coulangeon (2009) and some of the aspects mentioned above; students need a strong and fast flow of data otherwise they tend to switch off.

This study reviewed two major characteristics of the media as opposed to the traditional educational pattern commonly followed in schools: on the one hand, students require dynamic and updated contents that correspond to the evolution of communication technologies, as social media offer on a daily basis. In this sense, ICTs for education continuously evolve by modifying their media. On the other hand, the audiovisual world is not effective in the treatment of the conceptual and the abstract (such as philosophical reflection), because the image is so powerful that it reduces or removes the content side. The media trends favor primary feelings (joy, pity, pain...), against the power of abstraction necessary for the development of formal thought.

Perhaps a new student profile is emerging:

- Students are swift in responding to stimuli, with gradual increases in information, practical and positivist vision.

- Dispersed and non-constant attention, resulting from a saturation of constant stimuli, typical of the audiovisual narrative and ubiquitous media.

- A superficial knowledge about reality, seen as a set mosaic that is not very structured or coherent.

- Tendency to develop habits of understanding without effort, without reflective empowerment, and little deep understanding of the problems.

\section{Conclusions}

Social media and its narrative strategies shape the way in which we convey information and they tend to get people used to their procedures. Both, students and teachers should be aware of the new profiles suggested by the context and the multimedia culture. In this framework, the way to transfer knowledge seems to be as important as the contents themselves.

This Mexican and Spanish research perspective may be a reference for other educational contexts since the results presented could be transferred and applied to other settings.

It seems that students feel that teaching is more attractive when it has an entertainment value, when it is addressed to the emotions, when unexpected events occur, or if content is "light", with explicit observable traits, and with a variety and fast display of images. 
It becomes necessary to incorporate new strategies into the educational model in order to supplement traditional schemes and educational resources. From this perspective, the way contents are presented and the methodologies used are extremely important. We believe that greater efficiency could be achieved if the educational process of teaching and learning would incorporate some of the following strategies:

- The demands and expectations that the teacher places on his or her students is also quite different in nature and quantity when compared with the low level of activity the media require. This must be reconsidered in some cases, as these expectations can lead students to reject the learning environment or even abandon their studies altogether.

- Teachers should also increase the variety of, and flexibility in, the presentation of contents without overwhelming students; promoting class discussion and personal expression, sometimes breaking the logical order of presentation to accommodate a sense of surprise and the unexpected.

- Increasing the sense of playfulness in school activities in order to support the presentation of content in schools.

- Schools must support their methodologies in a more iconic way, when it can be relevant towards the content and the student profile.

- Creating emotionally appealing didactic materials. Teachers must look for the emotional aspects, relating them to the students' feelings.

- Planning how to win potential clients/students. Using intelligent teaching strategies or learning objects designed for each student's needs. Increasing the proximity and access to the student's home through technology, using virtual learning environments, discussion forums, personal messages, chat network systems with images (since it's a technique widely used in communication among students).

These results come to reinforce the idea that the introduction of ICTs in the teaching / learning process is not enough in order to guarantee innovation and improvement from a pedagogical point of view. The complexity and scattering of information and the different formats in which it can be transferred require a suitable framework and a specific methodology intended to grant the educational application of these systems. It is necessary to find a meeting point for new technologies and didactic and pedagogical issues. Information and Communication Technologies allow reaching certain cognitive and affective domains and they lead to the introduction of specific educational patterns that meet the demands of the new profiles of children and teenagers.

\section{References}

Briggs, L. (2007). A Second Life for middle school science. T.H.E Journal. Retrieved from http://www.thejournal.com/articles/20363

Caspi, A., Gorsky, P., \& Privman, M. (2005). Viewing comprehension: Students' learning preferences and strategies when studying from video. Instructional Science, 33(1), 31-47. 47. http://dx.doi.org/10.1007/s11251-004-2576-x

Castillo, J. M. (2004). Television y lenguaje audiovisual. Madrid: IORTV.

Chan, T., Roschelle, J., Sherry, H., Kinshuk, Sharples, M., Brown, T., ... Hoppe, U. (2006). One-to-one technology-enhanced learning: An opportunity for global research collaboration. Research and Practice in Technology Enhanced Learning, 1(1), 3-29. http://dx.doi.org/10.1142/S1793206806000032

Chenail, R. J. (2011). YouTube as a qualitative research asset: Reviewing user generated videos as learning resources. The Qualitative Report, 16(1), 229-235.

Coulangeon, P. (2009). Reading and Television-Watching: Changes in the cultural role of the school in the age of mass education. Revue Francaise de Sociologie, 50, 125-157.

De Waard, I. (2007). Vodcasting in Education 2.0. Berlin: Proceedings Online Educa.

Eren, M., Kollecker, M., Clarkson, C., \& Bradley, B. (2010). Dynamic approaches to teaching lithic technology: Using YouTube in the classroom. Ethnoarchaeology, 22, 223-233.

Everhart, J. (2010). YouTube in the science classroom: tips on incorporating this popular video file-sharing website into your science lessons. Science and Children 46.9 (2009). 32. Educator's Reference Complete. Web. 9 Feb. 2010.

Ferrell, O. C., \& Hartline, M. D. (2006). Estrategia de marketing. Mexico: Cengage Learning Editores.

Fombona, J. (2008). Lectura de imagenes y contenidos. Madrid: CEP. 
Fu, W. (2006). Concentration and homogenization of international movie sources: Examining foreign film $\begin{array}{llll}\text { import profiles. Journal of } & \text { 813-835. }\end{array}$ http://dx.doi.org/10.1111/j.1460-2466.2006.00321.x

Gamboa, C., \& Reina, M. (2006). Habitos de lectura, asistencia a bibliotecas y consumo de libros en Colombia. Bogota: Fundalectura.

Gernard, M., \& Klinger, W. (2007). Medienerzierhung in der zukunft. Frankfut, Media Perspectiven, 307.

Hall, S. (1981). La cultura, los medios de comunicacion y el «efecto ideologico». In Curran J. et al. (comp.) Sociedad y comunicacion de masas. Mexico: Fondo de Cultura Economica.

Hassett, K. (2007). Virtual worlds an outlet for learning, teaching. The Columbus Dispatch. Retrieved from http://www.columbusdispatch.com/live/contentbe/dispatch/2007/02/26/20070226-A4-02.html

Hill, J. A. (2011). Endangered childhoods: how consumerism is impacting child and youth identity. Media, Culture \& Society, 33(3), 347-362. http://dx.doi.org/10.1177/0163443710393387

Huston, A. C., Wright, J. C., Marquis, J., \& Green, S. (1999). How young children spend their time: Television and other activities. Developmental Psychology, 35(4), 912-925.

Hwang, G., Kuo, F., Yin, P., \& Chuang, K. (2010). A Heuristic Algorithm for planning personalized learning paths for context-aware ubiquitous learning. Computers \& Education, 54(2), http://dx.doi.org/10.1016/j.compedu.2009.08.024

Jones, A. Y. M., Dean, E., \& Hui-Chan, C. (2010). Comparison of teaching and learning outcomes between video-linked, web-based, and classroom tutorials: An innovative international study of profession education in physical therapy. Computers \& Education, 54(4), 1193-1201. http://dx.doi.org/10.1016/j.compedu.2009.11.005.

Jones, C., \& Healing, G. (2010). Networks and locations for student learning. Learning Media and Technology, 35(4), 369-385. http://dx.doi.org/10.1080/17439884.2010.529914

Kantar (2011). Boletines de audiencia. Ranking de programas. Retrieved from http://www.kantarmedia1.es/sections/audiencia/mensual

Kenwat, J., \& Bullen, E. (2001). Consuming children: education, entertainment, advertising. Buckingham: Open University Press.

Kraaykamp, G., Eijck, K., Ultee, W., \& Rees, k. (2007). Status and media use in the Netherlands - Do partners affect media tastes? Poetics, 35(2-3), 132-151.

Liaw, S, Hatala, M., \& Huang, H. (2010). Investigating acceptance toward mobile learning to assist individual knowledge management: Based on activity theory approach. Computers \& Education, 54(2), http://dx.doi.org/10.1016/j.compedu.2009.08.029

Liu, Y., Wang, X. H., \& Liu, C. X. (2009). Scalable Video Streaming in Wireless Mesh Networks for Education. New York: Ieee.

MacDonald, M. (2006). Empire and communication: the media wars of Marshall McLuhan. Media, Culture \& Society, 28(4), 505-520. http://dx.doi.org/10.1177/0163443706062912

Mann, P., Wong, D., \& Park, K. S. (2009). Innovative use of Vodcast (Video-Podcast) to Enrich Learning Experience in Structures Laboratory. Toronto: Nr. Reading Academic Conferences Ltd.

Marin, D., \& Mohan, P. (2009). Personalisation in mobile learning. International Journal of Mobile Learning and Organisation, 3(1). http://dx.doi.org/10.1504/IJMLO.2009.023051

Marsh, B., Mitchell, N., \& Adamczyk, P. (2010). Interactive video technology: Enhancing professional learning in initial teacher education. Computers \& Education, 54(3), 742-748, http://dx.doi.org/10.1016/j.compedu.2009.09.011

Meawad, F., \& Stubbs, G. (2008). A framework for enabling on-demand personalised mobile learning. International Journal of Mobile Learning and Organisation, 2(2), http://dx.doi.org/10.1504/IJMLO.2008.019765

Miglino, O., \& Walker, R. (2010). Teaching to teach with technology, a project to encourage take-up of advanced technology in education. In H. Uzunboylu (Ed.), Innovation and Creativity in Education, 2, 2492-2496. 
Murgatroud, S., \& Colin. (2002). La gestion de la calidad total en el centro docente. Madrid: Ramon Areces.

Murphy, S., Frank, L. B., Moran, M. B., \& Patnoe-Woodley, P. (2011). Involved, transported, or emotional? Exploring the determinants of change in knowledge, attitudes and behavior in entertainment-education. Journal of Communication, 61(3), 407-431. http://dx.doi.org/10.1111/j.1460-2466.2011.01554.x

Okamoto, T., Cristea, A., \& Kayama, M. (2001). Future integrated learning environments with multimedia. Journal of Computer Assisted Learning, 17(1), 4-12. http://dx.doi.org/10.1111/j.1365-2729.2001.00154.x

Orland, K. (2006). Harvard class invades Second Life. Joystiq. Retrieved September, from http://www.joystiq.com/2006/09/12/harvard-class-invades-second-life

Pelgrum, W. J. (2001). Obstacles to the integration of ICT in education: results from a worldwide educational assessment. Computers \& Education, 37(2), 163-178. http://dx.doi.org/10.1016/s0360-1315(01)00045-8

Pelgrum, W. J., \& Voogt, J. M. (2000). Information and communication technology (ICT) in lower secondary schools in Bulgaria, the Czech Republic, Hungary, Lithuania, and the Russian Federation. Etr \& D-Educational Technology Research and Development, 48(3), 111-121. http://dx.doi.org/10.1007/BF02319862

Peng, H., Su, Y., Chou, Ch., \& Tsai, Ch. (2009). Ubiquitous knowledge construction: mobile learning re-defined and a conceptual framework. Innovations in Education \& Teaching International, 46(2), 171-183. http://dx.doi.org/10.1080/14703290902843828.

Prensky, M. (2008). Turning on the lights, Educational Leadership, 65(6), 40-45.

Proserpio, L., \& Viola, D. (2007). Teaching the virtual generation. Academy of Management Learning $y$ Education, 6(1), 69-80. http://dx.doi.org/10.5465/AMLE.2007.24401703

Renes, R. J., Mussaers, K., \& Woerkum, C. (2011). The difficult balance between entertainment and education: a qualitative evaluation of a dutch health-promoting documentary series. Health Promot Pract. June 15. http://dx.doi.org/10.1177/1524839910390313

Richardson, W. (2006). The new face of learning. Retrieved from http://www.edutopia.org/magazine/ed1 article.php?id=Art 1648\&issue $=$ oct 06

Robinson, J. P., \& Martin, S. (2008). What do happy people do? Social Indicators Research, 89(3), 565-571.

Rockwell, S. C., \& Singleton, L. A. (2007). The effect of the modality of presentation of streaming multimedia $\begin{array}{llll}\text { on information acquisition. Media Psychology, } & \text { 9(1), }\end{array}$ http://dx.doi.org/10.1080/15213260709336808

Samaniego, M. (2008). Television and education: from entertainment to learning. Teoria de la Educacion, 20, 205-224.

Sevillano-Garcia, M. L. (2008). Nuevas tecnologias en educacion social. Madrid: McGraw Hill.

Shahid, M. K., \& Tang, S. L. (2007). Convergence and Technological Innovations in ICT Industry: Trends and Strategies for Operators. 2007 International Conference on Wireless Communications, Networking and Mobile Computing, 1-15, 6456-6459.

Spring, J. (2008). Research on globalization and education. Review of Educational Research, 78(2), 330-363. http://dx.doi.org/10.3102/0034654308317846

Upadhyay, N. (2006). M-Learning a new paradigm in education. International Journal of Instructional Technology y Distance Learning, 3(2). Retrieved from http://itdl.org/Journal/Feb_06/article04.htm

Ward, I. (2008). Labor's pitch to Generation YouTube. Social Alternatives, 27(2), 11-15.

Winn, W. (2002). Research into practice - Current trends in educational technology research: The study of learning environments. Educational Psychology Review, 14(3), UNSP pp504-edpr-374336.

Yalcin, S., Tugrul, B., Naçar, N., Tuncer, M., \& Yurdakök, K. (2002). Factors that affect television viewing time in preschool and primary school children. Pediatrics International, 44(6), 622-627.

Yen, Y. (2008). YouTube looks for the money clip. Fortune CNN Techland. Retrieved from http $\mathrm{http}$ //techland.blogs.fortune.cnn.com/2008/03/25/youtube-looks-for-the-money-clip/ 